\title{
Correlating Whole-Body Bone Mineral Densitometry Measurements to Those From Local Anatomical Sites
}

\author{
Alireza Rajaei, ${ }^{1}$ Pooneh Dehghan, ${ }^{2, *}$ Saideh Ariannia, ${ }^{1}$ Arman Ahmadzadeh, ${ }^{1}$ Madjid Shakiba, ${ }^{3}$ \\ and Kourosh Sheibani ${ }^{4}$ \\ ${ }_{2}^{1}$ Department of Rheumatology, Loghman e Hakim Hospital, Shahid Beheshti University of Medical Sciences, Tehran, Iran \\ ${ }_{3}^{2}$ Department of Imaging, Research Development Center, Taleghani Hospital, Shahid Beheshti University of Medical Sciences, Tehran, Iran \\ 3 Advanced Diagnostic and Interventional Radiology Research Center (ADIR), Tehran University of Medical Sciences, Tehran, Iran \\ ${ }^{4}$ Clinical Research and Development Center, Imam Hossein Medical Center, Shahid Beheshti University of Medical Sciences, Tehran, Iran \\ ${ }^{*}$ Corresponding author: Pooneh Dehghan, Department of Imaging, Research Development Center, Taleghani Hospital, Shahid Beheshti University of Medical Sciences, Tehran, Iran. \\ Tel:+98-9123130026, E-mail:p.dehghan@sbmu.ac.ir \\ Received 2014 December 10; Revised 2015 May 31; Accepted 2015 July 15.
}

\begin{abstract}
Background: Using the same cutoff points for whole-body measurements as for site-specific measurements will result in underestimation of osteoporosis.

Objectives: We assessed the correlation between densitometry measurements for the whole body with those for the femur, lumbar spine, and forearm to evaluate the possibility of replacing site-specific values with whole-body measurements.

Patients and Methods: In this cross-sectional study, we evaluated all patients referred to a single rheumatology clinic for bone mineral density measurements from 2009 to 2010. All patients who had bone mineral density measurements taken from the hip, lumbar spine, forearm, and whole body were enrolled in the study. Standard bone mineral density measurements were performed using a dual energy X-ray absorptiometry device (Hologic Delphi A; Hologic, Bedford, MA, USA). Bone mineral density, Z-score, and T-score were measured for all patients and all body regions.

Results: The mean age of the 152 participating patients was $56.7 \pm 12.6$ years, and $97.4 \%$ were female. Pearson correlation coefficients of the whole-body bone mineral density values compared with site-specific values in patients over age 50 were $0.66-0.75$. Using T-score cutoff points of -1 and -2.5 for osteopenia and osteoporosis, whole-body measurements underestimated the percentage of abnormal patients compared with the site-specific measurements (all $\mathrm{P}<0.001$ ). Using receiver operating characteristic (ROC) analysis, the whole-body bone mineral density showed respective areas under the curve of 0.96 and 0.84 for the diagnosis of abnormal hip bone mineral density and osteoporosis.

Conclusion: Using the same cutoff points for whole-body measurements as for site-specific measurements will result in overestimation or especially underestimation of osteopenia and osteoporosis diagnosis. Choosing new and appropriate cutoff points for whole-body densitometric measurements when we want to substitutes this assessment instead of site specific measurements seems mandatory and will decrease the rate of false diagnoses of densitometric deficiencies in these anatomical sites.
\end{abstract}

Keywords: Bone, Osteopenia, Osteoporosis, Diagnostic Imaging, Densitometry

\section{Background}

Bone mineral density (BMD) measurements are the main determinant for an osteoporosis diagnosis (1). The gold standard for BMD measurements is bone ash assessment, but its noninvasive substitute is dual-energy x-ray absorptiometry (DXA) $(1,2)$. DXA can be performed locally or for the whole body (2); however, the usual method of BMD measurement is the assessment of specific skeletal regions. The best areas for BMD assessment are the hip, lumbar spine, and forearm (3). It has been previously recommended that the BMD of the femoral neck, trochanter, and total hip, as well as the lumbar spine, should be measured, with the lowest value selected as the basis for treatment planning $(1,4)$; however, some reports have advised against this method (5). Occasionally, BMD measurements of the spine or other regions of interest are not feasible or could yield false results. For example, BMD may be overestimated in patients with spondylosis $(5,6)$; this could be due to osteophyte formation, which falsely increases the average BMD, while the patient may have a lower bone density in other parts of the spine, predisposing him or her to fracture (6). Thus, some authors have proposed whole-body BMD measurements instead of local measurements. However, questions remain regarding the accuracy and validity of a whole-body BMD measurement as a guide for spinal BMD and the associated fracture risk. Some authors have shown a good correlation between whole-body and local BMDs (2), while other authors have reported only a weak correlation (3). BMD measurements of different parts of the skeleton could also give different results, as bone loss is not a homoge-

Copyright (C) 2016, Tehran University of Medical Sciences and Iranian Society of Radiology. This is an open-access article distributed under the terms of the Creative Commons Attribution-NonCommercial 4.0 International License (http://creativecommons.org/licenses/by-nc/4.0/) which permits copy and redistribute the material just in noncommercial usages, provided the original work is properly cited. 
nous process (2). For instance, it has been shown that the BMD of the spine varies, and estimating the fracture risk of a particular region according to BMD measurements of other regions could be misleading (1).

\section{Objectives}

In this study, we evaluated the correlation between whole-body and local BMD assessments of the lumbar spine, hip, and forearm, to determine if whole-body BMD measurements could be used instead of local BMD measurements.

\section{Patients and Methods}

In this cross-sectional study, we evaluated all patients who were referred to a single rheumatology clinic for BMD measurements during the period of $2009-2010$. Patients who had BMD measurements taken of the hip, lumbar spine, forearm, and the whole body were included in the study. The study was approved by the ethics committee of Shahid Beheshti University of Medical Sciences. The exclusion criteria were: increasing or decreasing pelvic and spinal BMD due to osteoarthritis, metal artifact, local skeletal sclerosis, lytic or sclerotic lesions, Paget's disease, fractures, vascular calcifications, the presence of contrast media, urolithiasis, scoliosis, or prior laminectomy. A total of 152 patients were enrolled in the study. Standard BMD measurements were performed using a DXA Hologic device (Hologic Delphi A; Hologic, Bedford, MA, USA). Spinal measurements were done at the level of L1-L4. Pelvic measurements included the whole pelvic bone and the femoral neck, and forearm measurements were also performed. BMD, Z-score, and T-score were measured for all patients and all body regions. BMD was measured as $\mathrm{g} / \mathrm{cm}^{2}$. Normal BMD was defined as a $\mathrm{T}>-1$ in post-menopausal women and patients over 50 years of age, and as a $\mathrm{Z}>-2$ in nonmenopausal women or patients under age 50. Osteopenia was defined as a $\mathrm{T}<-1$ in post-menopausal patients or those over age 50 , and as a $\mathrm{Z}<-2$ in non-menopausal women or patients under age 50 . In patients over age 50 , a $\mathrm{T} \leq-2.5$ was considered to indicate osteoporosis. The following guidelines were used to categorize the patients (4):

1-Normal: $\mathrm{T} \leq-1 \times \mathrm{SD}$

2- Low bone mass (osteopenia): $-2.5 \times \mathrm{SD}<\mathrm{T}<-1 \times \mathrm{SD}$

3- Osteoporosis: $\mathrm{T} \leq-2.5 \times \mathrm{SD}$

4- Severe or established osteoporosis: a value for BMD of $2.5 \times$ SD or more below the mean for young adult females in the presence of one or more insufficiency fractures.

The manufacturer's standard values were used for calculating the T-score and Z-score.

\subsection{Statistical Analyses}

Normal data distribution and correlation of different BMD measurements were assessed by the Kolmogorov-
Smirnov test and Pearson's correlation coefficient, respectively. Local BMD estimations according to wholebody values were done using linear regression models. Assessment of the mean difference between continuous variables was performed by repeated ANOVA. The difference between nominal variables among patients was calculated using the McNemar test. Agreement of different variables was assessed and interpreted by kappa coefficient of agreement (7). All P values lower than 0.05 were considered statistically significant. All analyses were performed using SPSS statistical software (version 16.0, SPSS Inc., Chicago, IL, USA).

\section{Results}

Of the 152 total patients, 148 were female (97.4\%), 134 of whom were post-menopausal (90.5\%). The mean patient age was $56.7 \pm 12.6$ years (range $25-88$ years), with 106 patients older than 50 years (69.7\%). The respective mean whole-body BMD, Z-score, and T-score were $1.1 \pm$ 0.12 (range $0.8-1.4$ ), $0.72 \pm 1.2$ (range $2.1-3.8$ ), and $-0.33 \pm$ 1.42 (range $-3.5-2.9$ ), respectively (Table 1 ). There was no statistically significant difference between genders with regard to age, BMD, Z-score, or T-score.

Repeated ANOVA showed that the mean BMDs of the four different sites were significantly different. This significant difference was also observed between all pairwise comparisons in the whole-body BMD test (all P < 0.0001). Both the T- and the Z-scores showed significant differences between measurements on the ANOVA test $(\mathrm{P}<0.0001)$; however, this was not confirmed in the Bonferroni correction $(\mathrm{P}=0.37$ and 0.23 ). Other pairwise comparisons, including comparisons of the whole-body BMD with the BMD from specific sites, were significantly different $(\mathrm{P}<0.007$ and 0.01 , respectively). The respective Pearson correlation coefficients of the whole-body BMD with the spine BMD, hip BMD, and forearm BMD were $0.73,0.75$, and 0.77 , respectively (all $\mathrm{P}<0.0001$ ) (Table 2 ).

\begin{tabular}{|c|c|c|c|}
\hline Region & Minimum & Maximum & Mean \pm SD \\
\hline $\begin{array}{l}\text { BMD lumbar spine (g/ } \\
\mathrm{cm}^{2} \text { ) }\end{array}$ & 0.6 & 1.65 & $0.92 \pm 0.16$ \\
\hline Z-score lumbar spine & -2.8 & 3 & $0.03 \pm 1.24$ \\
\hline T-score lumbar spine & -3.8 & 4 & $-1.14 \pm 1.41$ \\
\hline BMD hip $\left(\mathrm{g} / \mathrm{cm}^{2}\right)$ & 0.44 & 1.08 & $0.73 \pm 0.13$ \\
\hline Z-score hip & -2.3 & 2.3 & $-0.19 \pm 0.96$ \\
\hline T-score hip & -3.7 & 1.1 & $-1.24 \pm 1.11$ \\
\hline BMD forearm $\left(\mathrm{g} / \mathrm{cm}^{2}\right)$ & 0.32 & 0.78 & $0.6 \pm 0.09$ \\
\hline Z-score forearm & -4.1 & 1.9 & $-0.29 \pm 1.15$ \\
\hline T-score forearm & -4.9 & 2.2 & $-1.49 \pm 1.48$ \\
\hline $\begin{array}{l}\text { BMD whole body (g/ } \\
\left.\mathrm{cm}^{2}\right)\end{array}$ & 0.8 & 1.36 & $1.07 \pm 0.12$ \\
\hline Z-score whole body & -2.1 & 3.8 & $0.72 \pm 1.16$ \\
\hline T-score whole body & -3.5 & 2.9 & $-0.33 \pm 1.42$ \\
\hline
\end{tabular}

Abbreviation: BMD, bone mineral density. 
The correlation coefficients of the whole-body Z-scores and T-scores related to local values are listed in Table 2. All correlation coefficients between local values were lower than 0.58 , except for the coefficient of 0.66 for the correlation of T-scores of the forearm and hip.

As densitometry is more important in women over age 50, we divided the patients into two groups: those over 50 and those equal or under 50 . We further divided these two main groups into two subgroups: those with normal $\mathrm{BMD}$, and those with abnormal BMD. The correlation coefficients of the whole-body indices with local parameters are listed in Table 2 . The results from a univariate regression model for the prediction of each local densitometry index according to the relevant whole-body measurement in patients over age 50 are shown in Table 3. With regard to predictions of the hip T-score according to the whole-body T-score, the $\mathrm{R}^{2}$ of the model was 0.61 .

As mentioned previously, subcategorization was done separately for the spine, hip, forearm, and whole-body BMD measurements in patients over age 50. Patients with normal and abnormal T-scores were cross-tabulated using the McNemar test to determine whether the frequency of patients with abnormal results for local measurements and whole-body measurements were equal. According to whole-body T-scores, 52 of 106 patients were osteopenic (49.1\%); in comparison, the numbers of osteopenic patients according to sitespecific T-scores for the spine, hip, and forearm were 68 (64.2\%), 75 (71.4\%), and 74 (69.8\%), respectively (Tables 4 and 5). Comparison of these percentages using the McNemar test showed that compared with all local densitometries, the whole-body results underestimated the percentage of patients with abnormal BMD (Table 5). A similar analysis was performed with a cutoff point of -2.5 for osteoporosis of all local and whole-body T-score measurements (Table 4 and 5).

Table 2. Pearson Correlation Coefficients of the Whole-Body BMD Indices with Similar Corresponding Local BMD Results Among All Patients and in Patients Under and Over Age 50

\begin{tabular}{|c|c|c|c|c|c|c|}
\hline \multirow[t]{2}{*}{ Reading } & \multicolumn{2}{|c|}{ Hip } & \multicolumn{2}{|c|}{ Spine } & \multicolumn{2}{|c|}{ Forearm } \\
\hline & Coefficient & P Value & Coefficient & PValue & Coefficient & P Value \\
\hline \multicolumn{7}{|l|}{ BMD } \\
\hline All patients & 0.75 & $<0.0001$ & 0.73 & $<0.0001$ & 0.77 & $<0.0001$ \\
\hline$\leq 50$ & 0.56 & $<0.0001$ & 0.7 & $<0.0001$ & 0.44 & $<0.0001$ \\
\hline$>50$ & 0.75 & $<0.0001$ & 0.66 & $<0.0001$ & 0.71 & $<0.0001$ \\
\hline \multicolumn{7}{|l|}{ Z-score } \\
\hline All patients & 0.66 & $<0.0001$ & 0.69 & $<0.0001$ & 0.68 & $<0.0001$ \\
\hline$\leq 50$ & 0.59 & $<0.0001$ & 0.71 & $<0.0001$ & 0.34 & 0.02 \\
\hline$>50$ & 0.74 & $<0.0001$ & 0.69 & $<0.0001$ & 0.7 & $<0.0001$ \\
\hline \multicolumn{7}{|l|}{ T-score } \\
\hline All patients & 0.81 & $<0.0001$ & 0.71 & $<0.0001$ & 0.78 & $<0.0001$ \\
\hline$\leq 50$ & 0.67 & $<0.0001$ & 0.72 & $<0.0001$ & 0.62 & $<0.0001$ \\
\hline$>50$ & 0.78 & $<0.0001$ & 0.6 & $<0.0001$ & 0.71 & $<0.0001$ \\
\hline
\end{tabular}

Abbreviation: BMD, bone mineral density

Table 3. Regression Models for Estimating BMD Measurements of Each Specific Anatomic Site According to the Whole-Body Measurement in Patients Over 50 Years of Age $\mathrm{e}^{\mathrm{a}, \mathrm{b}}$

\begin{tabular}{|c|c|c|c|c|}
\hline \multirow{3}{*}{ Dependent Variable } & \multirow{3}{*}{ Independent Variable } & \multicolumn{3}{|c|}{ Model Summary } \\
\hline & & \multirow[t]{2}{*}{$\mathbf{R}^{2}$} & \multicolumn{2}{|c|}{ Non-Standardized Coefficients } \\
\hline & & & B & Standard Error \\
\hline Spine BMD & Whole-Body BMD & 0.44 & $-0.09,0.94$ & $0.11,0.11$ \\
\hline Forearm BMD & Whole-Body BMD & 0.51 & $-0.005,0.55$ & $0.06,0.05$ \\
\hline Hip BMD & Whole-Body BMD & 0.56 & $-0.15,0.82$ & $0.07,0.07$ \\
\hline Spine Z-Score & Whole-Body Z-Score & 0.48 & $-0.39,0.76$ & $0.1,0.08$ \\
\hline Forearm Z-Score & Whole-Body Z-Score & 0.49 & $-0.8,0.74$ & $0.1,0.07$ \\
\hline Hip Z-Score & Whole-Body Z-Score & 0.55 & $-0.46,0.61$ & $0.07,0.06$ \\
\hline Spine T-Score & Whole-Body T-Score & 0.36 & $-0.99,0.64$ & $0.13,0.08$ \\
\hline Forearm T-Score & Whole-Body T-Score & 0.5 & $-1.3,0.78$ & $0.12,0.08$ \\
\hline Hip T-Score & Whole-Body T-Score & 0.61 & $-1,0.64$ & $0.08,0.05$ \\
\hline
\end{tabular}

Abbreviation: BMD, bone mineral density

$\mathrm{a}_{\text {Pvalue }<0.0001 .}$

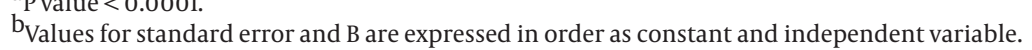


Table 4. Comparison of Abnormal BMD Frequency Determined by Each Anatomic Site Measurement in Patients Over Age 50

\begin{tabular}{|lc}
\hline Anatomic Site & No. $(\%)$ \\
\hline Hip & $75(71.4)$ \\
\hline Abnormal BMD & $24(22.9)$ \\
\hline Osteoporosis & \\
\hline Spine & $68(64.2)$ \\
\hline Abnormal BMD & $33(31.4)$ \\
\hline Osteoporosis & \\
\hline Forearm & $74(69.8)$ \\
\hline Abnormal BMD & $42(40)$ \\
\hline Osteoporosis & \\
\hline Whole Body & $52(49.1)$ \\
\hline Abnormal BMD & $10(9.5)$ \\
\hline Osteoporosis
\end{tabular}

Abbreviation: BMD, bone mineral density

Next, we classified the patients as normal, osteopenic, or osteoporotic based on their T-scores. As it was possible for a single patient to fit into multiple categories based on T-scores from different areas, the kappa agreements according to this categorization were measured (Table 6). In all instances, the kappa agreement coefficient was lower than 0.5 (Table 6). Based on the above mentioned analyses, it could be proposed that the considering similar cutoff points of -1 and -2.5 for whole body densitometry T-scores ensues in misleading assessment results. So in next step, we evaluated the diagnostic indices of whole body densitometry when we considered the T-score cutoff points of -1 for osteopenia and -2.5 for osteoporosis (exactly similar to cutoff points in site specific densitometry). For this assessment, we considered the results of each individual site as the gold standard, and generated the diagnostic indices of whole-body measurements for the diagnosis of an abnormal T-score $(\mathrm{T}<-1)$ and osteoporosis $(\mathrm{T}<$ -2.5) separately (Table 7). In addition, Kappa coefficients of agreement are presented in Table 7, demonstrating more than 30\% underestimation of abnormal results
Table 5. Comparison of Abnormal BMDs of Different Anatomical Sites and Whole Body

\begin{tabular}{|lc|}
\hline Comparison & P Value \\
\hline Hip versus spine & \\
\hline Abnormal BMD & 0.05 \\
\hline Osteoporosis & 0.16 \\
\hline Hip versus Forearm & \\
\hline Abnormal BMD & 0.15 \\
\hline Osteoporosis & 0.004 \\
\hline Hip versus whole body & \\
\hline Abnormal BMD & $<0.0001$ \\
\hline Osteoporosis & 0.001 \\
\hline Spine versus Forearm & \\
\hline Abnormal BMD & 0.08 \\
\hline Osteoporosis & 0.22 \\
\hline Spine versus whole body & \\
\hline Abnormal BMD & 0.002 \\
\hline Osteoporosis & $<0.0001$ \\
\hline Whole body versus forearm & $<0.0001$ \\
\hline Abnormal BMD & $<0.0001$ \\
\hline Osteoporosis & \\
\hline Abbreviation: BMD, bone minel & \\
\hline
\end{tabular}

Abbreviation: BMD, bone mineral density

when using whole-body T-scores with similar cutoff points as opposed to site-specific T-scores (Table 7).

So we assessed the diagnostic accuracy of all wholebody indices for the diagnosis of abnormal densitometry and osteoporosis using receiver operating characteristic (ROC) analysis yielded an area under the curve (AUC) for each site. In this regard, we had six different situations for each site (spine, hip, and forearm). For each site, we considered the results of the densitometry as the gold standard and calculated the AUC for BMD, Z-score, and T-score (Table 8). According to the AUC results, the best measurement for diagnosis of site specific abnormal BMD and osteoporosis was the wholebody BMD in diagnosing low BMD and osteoporosis in hip based on T-score (AUC $=0.96$ and 0.86 , respectively). In both of these ROCs, we considered two cutoff points, -0.5 and -1 , for calculating the diagnostic indices. At the cutoff point of -0.5 , the sensitivity and specificity of the test for diagnosis of abnormal BMD were 91 and 90, respectively. When using the cutoff point of -1, the respective sensitivity and specificity were 96 and 58 for a diagnosis of osteoporosis (Tables 9 and 10) (Figure 1A and B).

\begin{tabular}{lccccc}
\hline Table 6. Kappa Agreement Coefficients Between Different Measurements & \\
\hline Measurement & Whole-Body vs. Spine & Whole-Body vs. Hip & $\begin{array}{c}\text { Whole-Body vs. } \\
\text { Forearm }\end{array}$ & $\begin{array}{c}\text { Spine vs. Hip } \\
\text { Spine vs. } \\
\text { Forearm }\end{array}$ & $\begin{array}{c}\text { Hip vs. } \\
\text { Forearm }\end{array}$ \\
\hline Kappa & 0.28 & 0.42 & 0.24 & 0.24 & 0.17 \\
\hline
\end{tabular}


Rajaei A et al.

\begin{tabular}{|c|c|c|c|c|c|c|c|c|c|}
\hline & & $\begin{array}{c}\text { Sen. } \\
(95 \% \mathrm{CI})\end{array}$ & $\begin{array}{c}\text { Spec. } \\
(95 \% \mathrm{CI}) \\
\end{array}$ & $\begin{array}{c}\text { PPV } \\
(95 \% \mathrm{CI})\end{array}$ & $\begin{array}{c}\text { NPV } \\
(95 \% \mathrm{CI})\end{array}$ & $\begin{array}{c}\text { PLR } \\
(95 \% \mathrm{CI}) \\
\end{array}$ & $\begin{array}{c}\text { NLR } \\
(95 \% \mathrm{CI}) \\
\end{array}$ & $\begin{array}{c}\text { Accuracy } \\
(95 \% \mathrm{CI})\end{array}$ & $\begin{array}{l}\text { Kappa } \\
(95 \% \mathrm{CI})\end{array}$ \\
\hline \multicolumn{10}{|c|}{ Abnormal T-Score (Osteopenia and Osteoporosis) vs. Normal } \\
\hline Spine vs. WB & $\begin{array}{c}\text { TP: 46, FN: } 21, \text { TN: } \\
\text { 33, FP: } 5\end{array}$ & $\begin{array}{c}69 \\
(57-80)\end{array}$ & $\begin{array}{c}87 \\
(72-96)\end{array}$ & $\begin{array}{c}90 \\
(79-97)\end{array}$ & $\begin{array}{c}61 \\
(47-74)\end{array}$ & $\begin{array}{c}5.2 \\
(2.3-12)\end{array}$ & $\begin{array}{c}2.8 \\
(1.9-4)\end{array}$ & $\begin{array}{c}75 \\
(66-83)\end{array}$ & $\begin{array}{c}0.51 \\
(0.35-0.66)\end{array}$ \\
\hline Hip vs. WB & $\begin{array}{c}\text { TP: 51, FN: } 24, \mathrm{TN}: \\
\text { 30, FP: } 0\end{array}$ & $\begin{array}{c}68 \\
(56-78)\end{array}$ & $\begin{array}{c}100 \\
(88-100)\end{array}$ & $\begin{array}{c}100 \\
(93-100)\end{array}$ & $\begin{array}{c}56 \\
(41-69)\end{array}$ & NA & $\begin{array}{c}3.1 \\
(2.2-4.3)\end{array}$ & $\begin{array}{c}77 \\
(68-85)\end{array}$ & $\begin{array}{c}0.55 \\
(0.41-0.69)\end{array}$ \\
\hline Forearm vs. WB & $\begin{array}{c}\text { TP: 46, FN:27, TN: } \\
27, \text { FP: } 5\end{array}$ & $\begin{array}{c}63 \\
(51-74)\end{array}$ & $\begin{array}{c}84 \\
(67-95)\end{array}$ & $\begin{array}{c}90 \\
(79-97)\end{array}$ & $\begin{array}{c}50 \\
(36-64)\end{array}$ & $\begin{array}{c}4 . \\
(1.8-9.2)\end{array}$ & $\begin{array}{c}2.3 \\
(1.6-3.2)\end{array}$ & $\begin{array}{c}70 \\
(60-78)\end{array}$ & $\begin{array}{c}0.40 \\
(0.24-0.56)\end{array}$ \\
\hline \multicolumn{10}{|c|}{ Osteoporosis vs. Others } \\
\hline Spine vs. WB & $\begin{array}{l}\text { TP: 6, FN: } 27, \\
\text { TN:68, FP: } 4\end{array}$ & $\begin{array}{c}18 \\
(7-35)\end{array}$ & $\begin{array}{c}94 \\
(86-98)\end{array}$ & $\begin{array}{c}60 \\
(626-88)\end{array}$ & $\begin{array}{c}72 \\
(61-80)\end{array}$ & $\begin{array}{c}3.3 \\
(1-10.8)\end{array}$ & $\begin{array}{c}1.2 \\
(1-1.4)\end{array}$ & $70(61-79)$ & $\begin{array}{c}0.16 \\
(0 .-0.33)\end{array}$ \\
\hline Hip vs. WB & $\begin{array}{c}\text { TP: } 8 \text {, FN: } 16, \text { TN: } \\
\text { 79, FP: } 2\end{array}$ & $\begin{array}{c}33 \\
(16-55)\end{array}$ & $\begin{array}{c}98 \\
(91-99)\end{array}$ & $\begin{array}{c}80 \\
(44-97)\end{array}$ & $\begin{array}{c}83 \\
(74-90)\end{array}$ & $\begin{array}{c}13.5 \\
(3.1-59.4)\end{array}$ & $\begin{array}{c}1.5 \\
(1.1-1.9)\end{array}$ & $83(74-90)$ & $\begin{array}{c}0.39 \\
(0.17-0.60)\end{array}$ \\
\hline Forearm vs. WB & $\begin{array}{c}\text { TP: 9, FN: 33, TN: } \\
\text { 62, FP: } 1\end{array}$ & $\begin{array}{c}21 \\
(10-37)\end{array}$ & $\begin{array}{c}98 \\
(91-99)\end{array}$ & $\begin{array}{c}90 \\
(56-99)\end{array}$ & $\begin{array}{c}65 \\
(55-75)\end{array}$ & $\begin{array}{c}13.5 \\
(1.8-102.8)\end{array}$ & $\begin{array}{c}1.3 \\
(1.1-1.5)\end{array}$ & $68(74-90)$ & $\begin{array}{c}0.23 \\
(0.08-0.37)\end{array}$ \\
\hline
\end{tabular}

Abbreviation: TP, true positive; FN, false negative; TN, true negative; FP, false positive; Sen., sensitivity; Spec., specificity; PPV, positive predictive value; NPV, negative predictive value; PLR, positive likelihood ratio; NLR, negative likelihood ratio; BMD, bone mineral density; WB, whole body; CI, confidence interval. ${ }^{a}$ All values are mentioned as percent except for PLR, NLR and Kappa.

Table 8. Area Under the ROC Curves for Different ROC Analyses Based on Whole-Body Measurements for Diagnosis of Abnormal BMD and Osteoporosis in the Studied Anatomical Sites ${ }^{\mathrm{a}}$

\begin{tabular}{lccc}
\hline & WB BMD & WB Z-score & WB T-score \\
\hline Spine & & & \\
\hline Abnormal BMD vs. Normal BMD & $0.86(0.79-0.94)$ & $0.86(0.82-0.96)$ & $0.84(0.77-0.92)$ \\
\hline Osteoporosis vs. Others & $0.82(0.74-0.9)$ & & $0.82(0.74-0.9)$ \\
\hline Hip & & $0.93(0.88-0.98)$ & $0.96(0.92-0.99)$ \\
\hline Abnormal BMD vs. Normal BMD & $0.96(0.92-0.99)$ & $0.74-0.91)$ & $0.84(0.76-0.93)$ \\
\hline Osteoporosis vs. others & $0.84(0.76-0.91)$ & $0.79(0.68-0.89)$ & $0.83(0.73-0.93)$ \\
\hline Forearm & & $0.75(0.66-0.84)$ \\
\hline $\begin{array}{l}\text { Abnormal BMD vs. Normal BMD } \\
\text { Osteoporosis vs. Others }\end{array}$ & $0.83(0.75-0.91)$ & $0.83(0.75-0.90)$ \\
\hline
\end{tabular}

Abbreviation: BMD, bone mineral density; WB, whole body; AUC, area under the curve.

${ }^{a}$ All numbers are AUCs and their 95\% confidence interval in parenthesis.

\begin{tabular}{|c|c|c|c|c|c|c|c|c|c|}
\hline & & $\begin{array}{c}\text { Sen } \\
(95 \% \mathrm{CI})\end{array}$ & $\begin{array}{c}\text { Spec } \\
(95 \% \mathrm{CI})\end{array}$ & $\begin{array}{c}\text { PPV } \\
(95 \% \mathrm{CI})\end{array}$ & $\begin{array}{c}\text { NPV } \\
(95 \% \mathrm{CI})\end{array}$ & $\begin{array}{c}\text { PLR } \\
(95 \% \mathrm{CI})\end{array}$ & $\begin{array}{c}\text { NLR } \\
(95 \% \mathrm{CI})\end{array}$ & $\begin{array}{c}\text { Accuracy } \\
(95 \% \mathrm{CI})\end{array}$ & $\begin{array}{l}\text { Kappa } \\
(95 \% \mathrm{CI})\end{array}$ \\
\hline \multicolumn{10}{|c|}{$\begin{array}{l}\text { Abnormal } \\
\text { T-Score vs. } \\
\text { Normal }\end{array}$} \\
\hline $\mathrm{T} \leq-0.5$ & $\begin{array}{l}\text { TP:68 FN:7 } \\
\text { TN:27 FP:3 }\end{array}$ & $\begin{array}{c}91 \\
(82-96)\end{array}$ & $\begin{array}{c}90 \\
(73-98)\end{array}$ & $\begin{array}{c}96 \\
(88-99)\end{array}$ & $\begin{array}{c}79 \\
(62-91)\end{array}$ & $\begin{array}{c}9.1 \\
(3.1-26.6)\end{array}$ & $\begin{array}{c}9.6 \\
(4.7-19.7)\end{array}$ & $\begin{array}{c}90 \\
(83-95)\end{array}$ & $\begin{array}{c}0.77 \\
(0.64-0.91)\end{array}$ \\
\hline $\mathrm{T} \leq-1$ & $\begin{array}{c}\text { TP:56 FN:19 } \\
\text { TN:29 FP:1 }\end{array}$ & $\begin{array}{c}74 \\
(63-84)\end{array}$ & $\begin{array}{c}97 \\
(83-99)\end{array}$ & $\begin{array}{c}98 \\
(91-99)\end{array}$ & $\begin{array}{c}60 \\
(45-74)\end{array}$ & $\begin{array}{c}22.4 \\
(3.2-154.5)\end{array}$ & $\begin{array}{c}3.8 \\
(2.6-5.8)\end{array}$ & $\begin{array}{c}81 \\
(72-88)\end{array}$ & $\begin{array}{c}0.6 \\
(0.46-0.75)\end{array}$ \\
\hline \multicolumn{10}{|c|}{$\begin{array}{l}\text { Osteoporosis } \\
\text { vs. Others }\end{array}$} \\
\hline $\mathrm{T} \leq-0.5$ & $\begin{array}{c}\text { TP:23 FN:1 } \\
\text { TN:33 FP:48 }\end{array}$ & $\begin{array}{c}96 \\
(79-99)\end{array}$ & $\begin{array}{c}41 \\
(30-52)\end{array}$ & $\begin{array}{c}32 \\
(22-44)\end{array}$ & $\begin{array}{c}97 \\
(85-99)\end{array}$ & $\begin{array}{c}1.6 \\
(1.3-2)\end{array}$ & $\begin{array}{c}9.8 \\
(1.4-67.8)\end{array}$ & $\begin{array}{c}53 \\
(33-63)\end{array}$ & $\begin{array}{c}0.21 \\
(0.11-0.32)\end{array}$ \\
\hline $\mathrm{T} \leq-1$ & $\begin{array}{c}\text { TP:23 FN:1 } \\
\text { TN:47 FP:34 }\end{array}$ & $\begin{array}{c}96 \\
(79-99)\end{array}$ & $\begin{array}{c}58 \\
(47-69)\end{array}$ & $\begin{array}{c}40 \\
(28-54)\end{array}$ & $\begin{array}{c}98 \\
(89-99)\end{array}$ & $\begin{array}{c}2.3 \\
(1.7-3)\end{array}$ & $\begin{array}{c}13.9 \\
(2-95.7)\end{array}$ & $\begin{array}{c}67 \\
(57-76)\end{array}$ & $\begin{array}{c}0.36 \\
(0.22-0.5)\end{array}$ \\
\hline
\end{tabular}

Abbreviation: TP, true positive; FN, false negative; TN, true negative; FP, false positive; Sen., sensitivity; Spec., specificity; PPV, positive predictive value; NPV, negative predictive value; PLR, positive likelihood ratio; NLR, negative likelihood ratio; BMD, bone mineral density; CI, confidence interval.

${ }^{a}$ All values are mentioned as percent except for PLR, NLR and Kappa. 


\section{Rajaei A et al.}

Table 10. Sensitivity and Specificity of the Whole-Body BMD for Diagnosis of Abnormal Hip BMD and Hip Osteoporosis in Different Cutoff Points

\begin{tabular}{|c|c|c|c|c|c|}
\hline \multicolumn{3}{|c|}{ For Abnormal Hip BMD } & \multicolumn{3}{|c|}{ For Hip Osteoporosis } \\
\hline Cutoff Point $(\leq)$ & Sensitivity & Specificity & Cutoff Point $(\leq)$ & Sensitivity & Specificity \\
\hline-1.05 & 0.68 & 1 & -2.9 & 0.21 & 1.000 \\
\hline-0.75 & 0.79 & 0.97 & -2.65 & 0.25 & 0.99 \\
\hline-0.55 & 0.88 & 0.93 & -2.25 & 0.38 & 0.98 \\
\hline-0.45 & 0.91 & 0.9 & -1.95 & 0.46 & 0.9 \\
\hline-0.15 & 0.92 & 0.83 & -1.75 & 0.63 & 0.84 \\
\hline 0.05 & 0.95 & 0.8 & -1.65 & 0.67 & 0.83 \\
\hline 0.15 & 0.96 & 0.77 & -1.35 & 0.71 & 0.73 \\
\hline 0.25 & 0.97 & 0.73 & -1.15 & 0.88 & 0.67 \\
\hline 0.65 & 0.99 & 0.53 & -0.95 & 0.96 & 0.58 \\
\hline 1.5 & 1 & 0.13 & 0.15 & 1 & 0.32 \\
\hline
\end{tabular}

Abbreviation: BMD, bone mineral density.
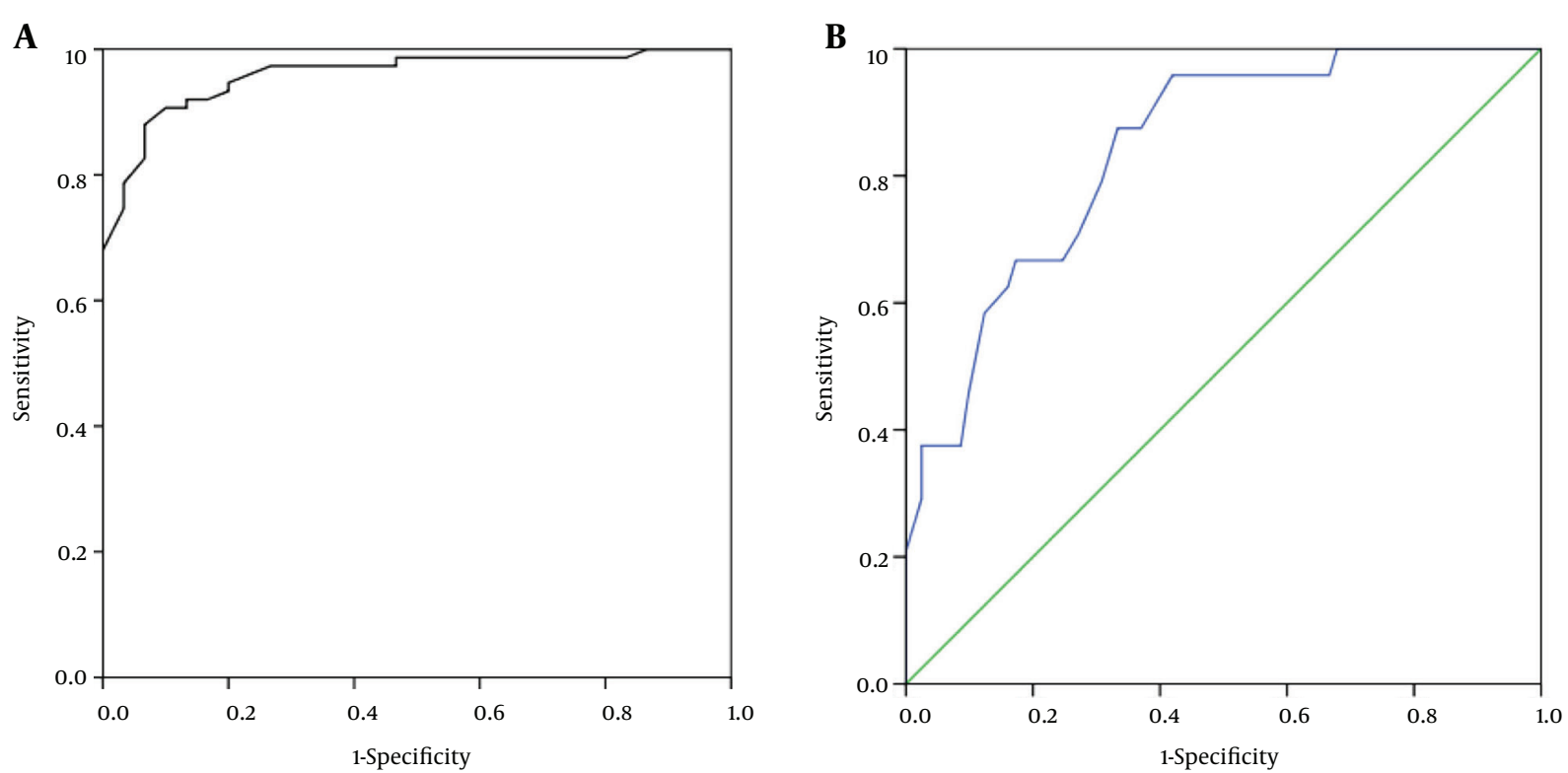

Figure 1. Analysis for diagnosis of hip densitometry abnormalities. A, ROC analysis for diagnosis of abnormal hip BMD according to whole-body BMD; B, ROC analysis for diagnosis of hip osteoporosis according to whole-body BMD.

\section{Discussion}

We found a significant difference between the mean BMD values for the whole-body versus local measurements. The correlations of whole-body measurements with the corresponding variables for each individual location were good; however, the regression model predictions of variables for each location using the corresponding whole-body values were not reliable. Using the same T-score cutoff points for diagnosis of abnormal BMD and osteoporosis from whole-body readings markedly underestimated abnormal BMD and osteoporosis according to hip BMD results. The AUC for diagnosing abnormal hip BMD from whole-body measurements was very promising; however, the profile for diagnosing osteoporosis was not as good. Different skeletal locations have been proposed for BMD assessment; some of these proposed sites are more generally recommended, while others are only recommended in certain circumstances, such as when the principal assessments are not feasible or could yield false results (4). The main sites that should be considered are the posteroanterior hip and the spine. Forearm measurements should be reserved for patients with hyperparathyroidism or morbid obesity, or in whom hip and/or spine measurements are not feasible or cannot be interpreted (4). Femoral neck assessment is preferred mainly because of osteoporotic femoral neck fracture morbidity, and the hip Tscore is the best predictor of femoral fracture. In addition, the hip has the greatest relevance to the clinical and biological aspects of osteoporosis (8). As noted earlier, BMD measurements can be associated with false re- 
Rajaei A et al.

sults; for example, the T-score will be falsely increased in osteoarthritis $(4,6)$. Thus, BMD assessment of other skeletal sites, such as the forearm and the whole body, has been proposed (4). The main issue is the validity and precision of whole-body BMD measurements for a diagnosis of osteoporosis in standard measurement sites, such as the lumbar spine and, especially, the hip and the femoral neck. Many studies have evaluated the concordance and discordance of BMD measurements of the hip and spine $(9,10)$. These studies have reported a high rate of discordance between the BMD values of the hip and spine, with findings of minor discordance (4\%) and major discordance of up to $40 \%$ between the BMD measurements for these two sites. Using the same T-score cutoff points for determining osteoporosis could make a difference in the perceived prevalence of osteoporosis; that is, an over- or underestimation of osteoporosis prevalence could result (3). This could lead to some difficulty in decision-making, as the T-scores could fall into two different world health organization (WHO) categories. Some physiologic and/or pathologic risk factors for this phenomenon include older age, menopause, and obesity $(9,10)$. Another possible reason could be the performance or analysis of the DXA (11). This over-or underestimation of osteoporosis prevalence could also result from considering whole-body BMD measurements, as various skeletal regions with different dynamic properties and types (for example, long bones versus cancellous bones) will be considered as one region. To account for this, some authors have introduced different cutoff points for the whole-body BMD definition of osteoporosis and osteopenia (12). Discordance of T-scores between the hip and spine could be due to the fact that age-related bone loss is nonhomogeneous (2). For example, it has been reported that lumbar spine BMD loss occurs at a younger age than hip BMD loss (3). In addition, osteoarthritis of the lumbar spine at older ages could interfere with the estimation of the real T-score (3). In this study, we employed different statistical approaches to assess the concordance and correlation of whole-body measurements with local values. Regarding the mean values, there was a significant difference between the mean values for whole-body versus local measurements. The correlation of whole-body measurements with the corresponding variables at each individual location were good; however, when considering the regression model results, the prediction of each variable from each specific location using the corresponding whole-body value did not seem perfect (all $\mathrm{R}^{2}$ values were lower than 0.65 ). At best, using a regression model to predict the hip Tscore from the whole-body T-score is associated with some incorrect classifications, which may interfere with choosing the correct treatment plan. Thus, using wholebody BMD measurements in this form is not acceptable. Using the same T-score cutoff points for the diagnosis of abnormal BMD and osteoporosis from whole-body readings markedly underestimated abnormal BMD (by 32\%) and osteoporosis (by 67\%) according to hip BMD results; this is probably because all bones affect the measurement in whole-body densitometry, including the long, wide, and spongiform bones (long bones could increase the mean of the densitometry measurement). This means that the values of the whole-body scan are generally higher than those from local regions, so using the whole-body T-score cutoff for determining osteoporosis underestimates the true result. To resolve this problem, we used the ROC curve analysis to assess the diagnostic performance of whole-body BMD measurements for the diagnosis of abnormal BMD and osteoporosis of the hip, as using other cutoff points may improve this misclassification. The AUC for diagnosing abnormal hip BMD was very promising (0.96), and we found a good cutoff point of -0.5 (instead of -1 ). The use of this cutoff point could yield a sensitivity of $90 \%$ and a specificity of $91 \%$, which seems to be acceptable. Similarly, the cutoff point of 0 yielded a sensitivity of $95 \%$ and specificity of $80 \%$ for diagnosing patients with abnormal hip BMD. The profile for diagnosing osteoporosis was not as good as for determining abnormal hip BMD; the AUC for determining osteoporosis was 0.84 (lower than the AUC of 0.96 for abnormal hip BMD), and the resulting diagnostic indices for this situation were insufficient for the diagnosis of abnormal BMD (sensitivity of $96 \%$ and specificity of $58 \%$ using the cutoff point of -1 ). Most previous studies assessing whole-body measurements have evaluated the correlation coefficient of whole-body versus local measurements (for example, the hip). The results of a study by Franck and Munz are in line with our study (2). However, our study yielded different results than Boyanov's, who studied 132 women (mean age 51 years) and estimated the lumbar spine BMD by DXA in standard anteroposterior scans, as well as the subregional analysis of whole-body measurements (12). Using the ROC method for the diagnosis of abnormal BMD and osteoporosis, Boyanov reported respective AUCs of 0.78 and 0.74 , which were lower than the AUCs in our study. At a sensitivity level of $90 \%$, Boyanov reported respective specificities of $83.5 \%$ and $70.5 \%$ for abnormal BMD and osteoporosis, which are again different from our findings. The possible reasons for these differences are that Boyanov derived the whole-body lumbar spine value instead of the whole-body measurement, the regression models from the previous study yielded a better fit and $\mathrm{R}^{2}$ in comparison to our study (all > 0.75), and there was a different age-range of patients (our study mainly involved patients older than 50 years). In addition, the kappa coefficient of agreement was greater than 0.6 in the previous study, which was better than that in our study. Discordance has also been shown in many other studies between the BMD results for different local areas, such as between the hip and spine. However, the value of this discordance is lower than for whole-body compared with local measurements; for example, Moayyeri et al. conducted a study of about 4,300 patients and reported 


\section{Rajaei A et al.}

a discordance of $40 \%$ between the hip and spine measurements (9). Cole and Larson reported a discordance of $5.4 \%$ when comparing the measurement of one hip to that of the contralateral hip (13). The limitations of this study were only minor. A larger sample size would have been favorable, and the chance to gather data from other clinics would have made the results more reliable.

At the end, we can conclude slight underestimation of abnormal BMD and osteoporosis should be considered in cases in which whole-body measurements are used instead of local measurements. This underestimation could be reduced by choosing appropriate cutoff points for the diagnosis of abnormal BMD and osteoporosis (different from the classic T-score cutoff points of -1 and -2.5 ); however, this would still not eliminate possible resultant misclassification.

\section{References}

1. Lewiecki EM, Kendler DL, Kiebzak GM, Schmeer P, Prince RL, ElHajj Fuleihan G, et al. Special report on the official positions of the International Society for Clinical Densitometry. Osteoporos Int. 2004;15(10):779-84. doi: 10.1007/s00198-004-1677-3. [PubMed: 15278247]

2. Franck H, Munz M. Total body and regional bone mineral densitometry (BMD) and soft tissue measurements: correlations of BMD parameter to lumbar spine and hip. Calcif Tissue Int. 2000;67(2):111-5. [PubMed: 10920214]

3. Graat-Verboom L, Spruit MA, van den Borne BEEM, Smeenk FWJM, Wouters EFM. Whole-Body versus Local DXA-Scan for the Diagnosis of Osteoporosis in COPD Patients. Journal of Osteoporosis. 2010;2010:1-6. doi: 10.4061/2010/640878.

4. Lewiecki EM, Watts NB, McClung MR, Petak SM, Bachrach LK, Shepherd JA, et al. Official positions of the international society for clinical densitometry. J Clin Endocrinol Metab. 2004;89(8):3651-5. doi:10.1210/jc.2004-0124. [PubMed:15292281]

5. Kanis JA, Johnell O, Oden A, Johansson H, Eisman JA, Fujiwara S, et al. The use of multiple sites for the diagnosis of osteoporosis. Osteoporos Int. 2006;17(4):527-34. doi:10.1007/s00198-005-0014-9. [PubMed:16402164]

6. Liu G, Peacock M, Eilam O, Dorulla G, Braunstein E, Johnston CC. Effect of osteoarthritis in the lumbar spine and hip on bone mineral density and diagnosis of osteoporosis in elderly men and women. Osteoporos Int. 1997;7(6):564-9. [PubMed: 9604053]

7. Chmura Kraemer H, Periyakoil VS, Noda A. Kappa coefficients in medical research. Stat Med. 2002;21(14):2109-29. doi: 10.1002| sim.1180. [PubMed: 12111890]

8. Kanis JA, World Health Organization. Assessment of osteoporosis at the primary health care level. WHO Collaborating Centre for Metabolic Bone Diseases, University of Sheffield Medical School; 2008.

9. Moayyeri A, Soltani A, Tabari NK, Sadatsafavi M, Hossein-neghad A, Larijani B. Discordance in diagnosis of osteoporosis using spine and hip bone densitometry. BMC endocrine disorders. 2005;5(1):3. [PubMed: 15762986]

10. Mounach A, Abayi DA, Ghazi M, Ghozlani I, Nouijai A, Achemlal L, et al. Discordance between hip and spine bone mineral density measurement using DXA: prevalence and risk factors. Semin Arthritis Rheum. 2009;38(6):467-71. doi: 10.1016/j.semarthrit.2008.04.001. [PubMed:18571696]

11. El Maghraoui A, Mouinga Abayi DA, Rkain H, Mounach A. Discordance in diagnosis of osteoporosis using spine and hip bone densitometry. J Clin Densitom. 2007;10(2):153-6. doi: 10.1016/j. jocd.2006.12.003. [PubMed:17485031]

12. Boyanov M. Estimation of lumbar spine bone mineral density by dual-energy X-ray absorptiometry: standard anteroposterior scans vs sub-regional analyses of whole-body scans. $\mathrm{Br} \mathrm{J} \mathrm{Ra-}$ diol. 2008;81(968):637-42. doi: 10.1259/bjr/22307093. [PubMed: 18628333]

13. Cole R, Larson J. The effect of measurement of the contralateral hip if the spine is not included in the bone mineral density analysis. J Clin Densitom. 2006;9(2):210-6. doi: 10.1016/j. jocd.2006.02.003. [PubMed: 16785083] 